\title{
A Prototype Quantitative Precipitation Estimation Algorithm for Operational S-Band Polarimetric Radar Utilizing Specific Attenuation and Specific Differential Phase. Part I: Algorithm Description
}

\author{
YADONG WANG \\ Department of Electrical and Computer Engineering, Southern Illinois University Edwardsville, \\ Edwardsville, Illinois, and Cooperative Institute for Mesoscale Meteorological Studies, \\ University of Oklahoma, and NOAA/OAR/National Severe Storms Laboratory, \\ Norman, Oklahoma \\ Stephen Cocks, Lin TAng, Alexander Ryzhkov, and Pengfei Zhang \\ Cooperative Institute for Mesoscale Meteorological Studies, University of Oklahoma, and NOAA/OAR/National \\ Severe Storms Laboratory, Norman, Oklahoma \\ JIAN ZHANG AND KENNETH HOWARD \\ NOAA/OAR/National Severe Storms Laboratory, Norman, Oklahoma \\ (Manuscript received 8 April 2018, in final form 24 February 2019)

\begin{abstract}
A prototype quantitative precipitation estimate (QPE) algorithm that utilizes specific attenuation $A$ and specific differential phase $K_{\mathrm{DP}}$ was developed for inclusion into the Multi-Radar Multi-Sensor (MRMS) system and the Weather Surveillance Radar-1988 Doppler (WSR-88D) network. Special attention is given to the optimization of the factor $\alpha$ used for computation of a path-integrated attenuation from a total span of differential phase along the propagation path in rain. It is suggested to estimate $\alpha$ from a slope of the $Z_{\mathrm{DR}}$ dependence on $Z$ in rain. The use of real-time adjusted $\alpha$ allows us to capture the variations of the drop size distributions, and therefore improve the QPE accuracy. It is demonstrated that the factor $\alpha$ is generally higher for tropical rain type compared to continental rain. Since the $R(A)$ approach is only valid for pure rainfall, the $R\left(K_{\mathrm{DP}}\right)$ relation is suggested as a complement in areas of hail contamination. The paper contains a description of the basic version of the $R(A)$ and $R\left(K_{\mathrm{DP}}\right)$ algorithm and recommendations for its further optimization.
\end{abstract}

\section{Introduction}

The methods for quantitative precipitation estimation (QPE) utilizing different combinations of radar reflectivity $Z$, differential reflectivity $Z_{\mathrm{DR}}$, and specific differential phase $K_{\mathrm{DP}}$ were developed during the last two decades (e.g., Ryzhkov and Zrnić 1995; Brandes et al. 2002; Bringi et al. 2011; Giangrande and Ryzhkov 2008; Wang et al. 2013). Among all of these approaches, the $R(Z)$ relations have been the most traditional methods used to estimate rainfall. However, the $R(Z)$ relations are very sensitive to the drop size distribution (DSD) variability and also affected by radar miscalibration and

\footnotetext{
Corresponding author: Yadong Wang, yadwang@siue.edu
}

attenuation (e.g., Testud et al. 2000; Gourley et al. 2009). A 1 -dB bias in $Z$ could cause a $\sim 15 \%$ bias in the estimated rainfall rate (Gourley et al. 2009). The use of combination of $Z$ and $Z_{\mathrm{DR}}$ can mitigate some of the uncertainties related to the DSD variability and results in the reduction of the QPE errors compared to conventional $R(Z)$ relations (e.g., Seliga and Bringi 1976; Gorgucci et al. 1994). However, biases in both $Z$ and $Z_{\mathrm{DR}}$ caused by miscalibration and attenuation can limit the $R\left(Z, Z_{\mathrm{DR}}\right)$ performance, particularly in heavy rain. Specific differential phase is immune to attenuation and radar miscalibration, and the $R\left(K_{\mathrm{DP}}\right)$ estimates are less sensitive to the DSD variations than the $R(Z)$ estimates, at least for moderate-to-heavy rain. However, the estimated $K_{\mathrm{DP}}$ is noisy in areas of weaker echoes, where 
$Z<30-40 \mathrm{~dB} Z$. Generally, at $\mathrm{S}$ band, the $R\left(K_{\mathrm{DP}}\right)$ relation is used in a mixture of rain and hail and the $R\left(Z, Z_{\mathrm{DR}}\right)$ relation in pure rain (Giangrande and Ryzhkov 2008; Cifelli et al. 2011; Chen et al. 2017). The $R\left(K_{\mathrm{DP}}\right)$ relation is utilized in a wide range of rain intensities at $\mathrm{C}$ and $\mathrm{X}$ bands complemented by $R(Z)$ in light rain (e.g., Park et al. 2005; Figueras i Ventura et al. 2012; Vulpiani et al. 2012; Yoshikawa et al. 2012; Chen and Chandrasekar 2015; Wang et al. 2016; Cifelli et al. 2018).

A novel rainfall estimation algorithm based on the use of specific attenuation $A$ was proposed by Ryzhkov et al. (2014). According to this algorithm, the $A$ field derived using the ZPHI method (e.g., Bringi et al. 1990; Testud et al. 2000; Bringi et al. 2001) is suggested to be directly used for the rain rate estimation as

$$
R=\gamma A^{\Lambda},
$$

where the coefficients $\gamma$ and $\Lambda$ depend on the radar wavelength, temperature, and polarization. Applications of the $R(A)$ relations for C-band and X-band polarimetric radars were also investigated by Wang et al. (2014), Giangrande et al. (2014), Boodoo et al. (2015), and Diederich et al. (2015). Although the $R(A)$ relation is less sensitive to the DSD variations than the $R(Z), R\left(Z, Z_{\mathrm{DR}}\right)$, and $R\left(K_{\mathrm{DP}}\right)$ relations, the impact of the DSD variability on the estimate of $A$ can still be significant. Indeed, the ZPHI routine requires the knowledge of the path-integrated attenuation (PIA) that is estimated from the total span of differential phase $\Phi_{\mathrm{DP}}$ along the propagation path in rain $\Delta \phi_{\mathrm{DP}}$ as

$$
\mathrm{PIA}=\alpha \Delta \Phi_{\mathrm{DP}}
$$

where the factor $\alpha$ is the net ratio of $A$ and $K_{\mathrm{DP}}$ along the path. Because the factor $\alpha$ is a function of DSD, temperature, and radar wavelength, it requires optimization for a particular rain type. For initial implementation of the $R(A)$ algorithm, Ryzhkov et al. (2014) recommended using the value of $\alpha$ equal to $0.015 \mathrm{~dB}$ per degree at $\mathrm{S}$ band. This value is a good choice for continental heavy rain characterized by high $Z_{\mathrm{DR}}$, but may not be optimal for tropical or light rain that is characterized by generally lower $Z_{\mathrm{DR}}$. Hence, real-time estimation of $\alpha$ matching the dominant precipitation regime should improve the performance of the $R(A)$ algorithm.

In this paper, the description of an operational version of the $R(A)$ algorithm is provided with a primary focus on the optimization and real-time estimation of the parameter $\alpha$. The $A$-based QPE method does not work in the presence of hail and has to be complemented with the $R\left(K_{\mathrm{DP}}\right)$ relation which is another issue discussed in the paper. The paper is organized as follows: section 2 contains a review of the $R(A)$ methodology and the key requirements for an automated prototype algorithm. The discussions on the optimization of $\alpha$ and estimation of rain rate in the presence of hail are also included in section 2. The description of the operational version of the algorithm is in section 3, and discussion and summary are given in sections 4 and 5 .

\section{The $R(A)$ methodology and the requirements for an automated prototype algorithm}

\section{a. Review of $R(A)$ methodology}

In their study, Ryzhkov et al. (2014) calculated radial profiles of $A$ using the measured reflectivity $Z_{a}$ and total span of differential phase $\phi_{\mathrm{DP}}$ between ranges $r_{1}$ and $r_{2}$ (Testud et al. 2000):

$$
\begin{aligned}
A(r) & =\frac{\left[Z_{a}(r)\right]^{\beta} C(\beta, \mathrm{PIA})}{I\left(r_{1}, r_{2}\right)+C(\beta, \mathrm{PIA}) I\left(r, r_{2}\right)}, \\
C(\beta, \mathrm{PIA}) & =\exp (0.23 \beta \mathrm{PIA})-1, \quad \text { and } \\
\operatorname{PIA}\left(r_{1}, r_{2}\right) & =\alpha\left[\phi_{\mathrm{DP}}\left(r_{2}\right)-\phi_{\mathrm{DP}}\left(r_{1}\right)\right],
\end{aligned}
$$

where $I\left(r_{1}, r_{2}\right)=0.46 \beta \int_{r_{1}}^{r_{2}}\left[Z_{a}(s)\right]^{\beta} d s$ and $I\left(r, r_{2}\right)=$ $0.46 \beta \int_{r}^{r_{2}}\left[Z_{a}(s)\right]^{\beta} d s$. The constant $\beta$ is usually within $0.6-0.9$ range at microwave frequencies and can be set equal to 0.62 for S-band radar. In Eq. (3), the variable $Z_{a}$ represents the measured radar reflectivity that is not corrected for miscalibration and attenuation. The radial profile of $A$ is calculated between $r_{1}$ and $r_{2}$, where $r_{1}$ is the first gate that contains precipitation, and $r_{2}$ is either the last precipitation gate or the gate immediately below the bottom of a melting layer, whichever is smaller.

Since $A$ is a function of the radar wavelength and raindrop temperature, the parameters of power-law $R(A)$ rainfall relations are also wavelength and temperature dependent (Ryzhkov et al. 2014), and the parameters of the $R(A)$ relation can change significantly even within a particular band $(\mathrm{S}, \mathrm{C}$, or $\mathrm{X})$. For the Weather Surveillance Radar-1988 Doppler (WSR-88D) radars operating at $\mathrm{S}$ band the multiplier $\gamma$ in the $R(A)$ relation increases by $35 \%$ as the radar wavelength $\lambda$ changes from 10.0 to $11.0 \mathrm{~cm}$ (Ryzhkov et al. 2014). The scatterplots of $R$ versus $A$ at $\lambda=10.0$ and $11.0 \mathrm{~cm}$ simulated using large disdrometer dataset at the temperature $20^{\circ} \mathrm{C}$ are shown in Fig. 1 . The corresponding multipliers $\gamma$ are 3056 and 4120, respectively, and both scatterplots exhibit very narrow spread.

At $\mathrm{S}$ band, the dependencies of the intercept on temperature and radar wavelength can be approximated by the formula (Ryzhkov et al. 2014) 

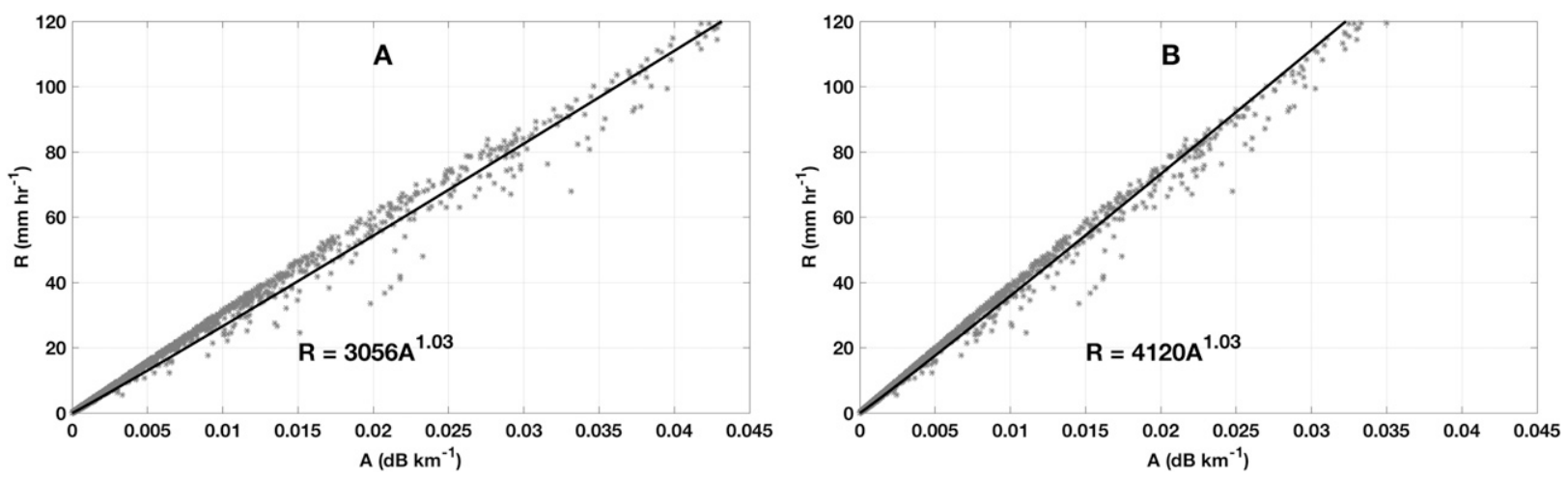

FIG. 1. The scatterplots of $R$ vs $A$ simulated for wavelengths of (a) 10 and (b) $11 \mathrm{~cm}$ at $20^{\circ} \mathrm{C}$ using a large disdrometer dataset. Linear fits are overlaid with solid lines.

$$
R(A)=c_{1}(T) c_{2}(\lambda) A^{1.03}
$$

where

$$
\begin{aligned}
& c_{1}(T)=\left(2.23+0.078 T+0.00085 T^{2}\right) 10^{3}, \quad \text { and } \\
& c_{2}(\lambda)=1-0.26(11.0-\lambda) .
\end{aligned}
$$

In Eqs. (6)-(8), $T$ is the temperature $\left({ }^{\circ} \mathrm{C}\right)$ and $\lambda$ is the radar wavelength $(\mathrm{cm})$.

Ryzhkov et al. (2014) showed that specific attenuation $A$ is approximately linearly dependent on $\alpha=$ $A / K_{\mathrm{DP}}$. Therefore, rain rate in Eq. (1) is proportional to the product $\gamma \alpha^{\Lambda}$. Because the exponent $\Lambda$ is very close to 1 , the wavelength/temperature dependencies of $\gamma$ and $\alpha$ almost perfectly cancel each other. In other words, since the intercept $\gamma$ increases with $\lambda$ and the factor $\alpha$ decreases with $\lambda$ in the same proportion, their product remains almost unchanged. A similar consideration is valid with respect to the temperature provided that the temperature dependence of $\alpha$ is taken into account and the temperature does not vary much along the propagation path in rain. This means that, to the first approximation, it is possible to use a single universal $R(A)$ relation in a given microwave frequency band and ignore the dependencies of the factors $\gamma$ and $\alpha$ on the radar wavelength and temperature (Ryzhkov et al. 2014; Wang et al. 2014; Diederich et al. 2015). A single $R(A)$ relation was proposed for the operational network of the S-band WSR-88D radars in the United States (Ryzhkov et al. 2014):

$$
R(A)=4120 A^{1.03}
$$

which is valid at $T=20^{\circ} \mathrm{C}$ and $\lambda=11.0 \mathrm{~cm}$. It should be noted that the temperature dependence of the intercept $\gamma$ should be taken into account if the temperature varies significantly $\left(>20^{\circ} \mathrm{C}\right)$ along the propagation path in rain.
The temperature impact on the performance of C-band $R(A)$ was investigated by Wang et al. (2014), and it was found that $18^{\circ} \mathrm{C}$ temperature variation may cause less than $15 \%$ bias on the obtained rainfall rate. It was also found that indistinguishable bias is caused by the temperature variation of $5^{\circ} \mathrm{C}$ if a single $R(A)$ relation is used at $\mathrm{X}$ band (Diederich et al. 2015).

The intercept $\gamma$ and the exponent $\Lambda$ in the $R(A)$ power-law relation (1) are practically unaffected by the DSD variability (at least at $\mathrm{S}$ band). However, the estimate of $A$ is affected by factor $\alpha$, and the optimization of $\alpha$ poses the biggest challenge of the $R(A)$ method. It has to be emphasized that this is also a problem for the polarimetric technique for attenuation correction, which prescribes estimation of the path integrated attenuation PIA using a total span of differential phase $\Delta \Phi_{\mathrm{DP}}$ along the propagation path (Bringi et al. 1990). The factor $\alpha$ (i.e., the ratio $A / K_{\mathrm{DP}}$ ) depends on differential reflectivity $Z_{\mathrm{DR}}$, and it monotonically decreases with increasing $Z_{\mathrm{DR}}$ at $\mathrm{S}$ band till reaching relatively stable value for $Z_{\mathrm{DR}}>1-1.5 \mathrm{~dB}$ (Fig. 2). A default value of $\alpha$ for continental rain commonly characterized by larger $Z_{\mathrm{DR}}$ is suggested as $0.015 \mathrm{~dB}$ per degree (Ryzhkov et al. 2014).

It was found that $\alpha$ varied from 0.02 to $0.03 \mathrm{~dB}$ per degree over most areas of the Hurricane Irene and was within $0.008-0.015 \mathrm{~dB}$ per degree for a central Oklahoma flash flood on 14 June 2010 (Ryzhkov et al. 2014). Because rain rate estimated from the $R(A)$ relation is roughly proportional to $\alpha$, the algorithm inevitably tends to underestimate tropical rain or light rain in general which are characterized by low values of $Z_{\mathrm{DR}}$ if a default value of $\alpha$ typical for continental rain is utilized. The problem can be addressed by an automatic adjustment of $\alpha$ based on $Z_{\mathrm{DR}}$ or a slope of the $Z_{\mathrm{DR}}$ dependence on $Z$ (a " $Z_{\mathrm{DR}}$ slope") as shown below. The use of the $Z_{\mathrm{DR}}$ slope is not affected by potential 


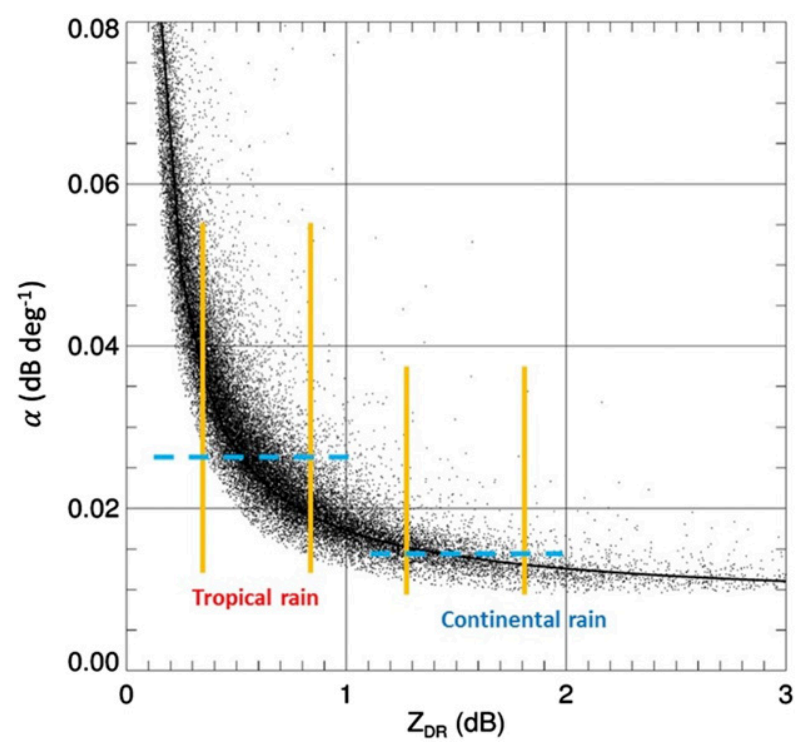

FIG. 2. The scatterplot of the factor $\alpha$ vs $Z_{\mathrm{DR}}$ simulated from the Oklahoma disdrometer dataset for the radar wavelength of $11.0 \mathrm{~cm}$ and temperature of $20^{\circ} \mathrm{C}$. Vertical yellow lines indicate the range of $Z_{\mathrm{DR}}$ variability for conceptual cases of tropical and continental rain. Horizontal dashed blue lines depict net values of $\alpha$ (dB per degree) for both rain types.

miscalibration of $Z_{\mathrm{DR}}$ and it better represents rain type in a large spatial/temporal domain than point measurements of $Z_{\mathrm{DR}}$.

\section{b. Estimating $\alpha$ using $Z_{\mathrm{DR}}$ slope}

\section{1) METHOD}

Because tropical rain is characterized by the abundance of small raindrops in high concentration (e.g., Chang et al. 2009, Thompson et al. 2015), the values of $Z_{\mathrm{DR}}$ (and $Z_{\mathrm{DR}}$ slope) in tropical rain are usually lower than in the continental rain at a given $Z$. This is demonstrated in Fig. 3 where the scatterplots of $Z_{\mathrm{DR}}$ versus $Z$ measured by the WSR-88D radar at Mobile, Alabama (KMOB), in different parts of a mesoscale convective system (MCS) on 29 April 2014 are shown. Prior to the analysis, all radar echoes caused by ground clutter, interference, and other nonprecipitation targets were removed by a physically based data quality control (QC) approach (Tang et al. 2014). In Figs. 3a-c, the collected pairs of $Z_{\mathrm{DR}}$ versus $Z$ have been classified as associated with either convective, stratiform, or tropical rain types based on the radar echo classification given by the Multi-Radar Multi-Sensor (MRMS) precipitation type algorithm (Zhang et al. 2016). All $Z-Z_{\mathrm{DR}}$ pairs were segregated into the 2-dBZ-wide $Z$ bins centered on even values ranging from 20 to $50 \mathrm{~dB} Z$. For each $Z$ bin, the median $Z_{\mathrm{DR}}$ was calculated and a linear regression fitting was obtained for the median $Z_{\mathrm{DR}}-Z$ pairs for the three rain types. The corresponding linear $Z_{\mathrm{DR}}-Z$ dependencies are displayed in Fig. 3d. A $Z_{\mathrm{DR}}(Z)$ slope for the $Z_{\mathrm{DR}}-Z$ pairs associated with convective rain is steeper than the slopes for stratiform and tropical pairs. For $Z$ at $40 \mathrm{~dB} Z$, the median $Z_{\mathrm{DR}}$ corresponding to the tropical, stratiform, and convective rain were $0.71,0.93$, and $1.52 \mathrm{~dB}$, respectively. Therefore, a slope of the dependence of $Z_{\mathrm{DR}}$ on $\mathrm{Z}$ can be used to determine a dominant rain type in the radar field of view (FOV).

The dependence of $\alpha$ on the $Z_{\mathrm{DR}}$ slope was determined using simulations based on a large DSD dataset collected by a 2D video disdrometer over a 7-yr period in Oklahoma (Schuur et al. 2001, 2005). A total of 47114 one-minute DSD data were collected from 20 April 1998 through 13 May 2005 (Schuur et al. 2005). In the simulation, the forward $\left[f_{a, b}(0)\right]$, and backward $\left[f_{a, b}(\pi)\right]$ scattering amplitudes from horizontal and vertical directions were first calculated using a T-matrix code (Mishchenko 2000), where " $a$ " and " $b$ " indicate the horizontal and vertical polarization, respectively. The aspect ratio of raindrop as a function of its equivolume diameter (Brandes et al. 2002), and the dielectric constant of water at $20^{\circ} \mathrm{C}$ are inputs into the T-matrix code. Values of $A, K_{\mathrm{DP}}, Z$, and $Z_{\mathrm{DR}}$ were then calculated using the procedures described by Ryzhkov et al. $(2011,2013)$ assuming that the width of the canting angle distribution of raindrops is $10^{\circ}$. All 47144 rain DSDs have been divided into 5 groups depending on the value of $Z_{\mathrm{DR}}$ for a given $Z$ (i.e., $0 \%-20 \%, 20 \%-40 \%$, $40 \%-60 \%, 60 \%-80 \%$, and $80 \%-100 \%$ percentile categories). For each category of DSD, a net value of $\alpha$ was estimated as a ratio $\sum A / \sum K_{\mathrm{DP}}$ where summation is performed over all DSDs in a particular category. A slope of $Z_{\mathrm{DR}}\left(K=d Z_{\mathrm{DR}} / d Z\right)$ was calculated as a difference $\left\langle Z_{\mathrm{DR}}(50)\right\rangle-\left\langle Z_{\mathrm{DR}}(20)\right\rangle$ divided by 30 , where $\left\langle Z_{\mathrm{DR}}(20)\right\rangle$ and $\left\langle Z_{\mathrm{DR}}(50)\right\rangle$ are the median values of $Z_{\mathrm{DR}}$ for $Z$ bins centered at 20 and $50 \mathrm{~dB} Z$ for a given category. A nonlinear fit to the $\alpha(K)$ dependence is presented by a blue dashed line in Fig. 4 (black triangles). This nonlinear fit can be also approximated by a bilinear dependence as

$$
\begin{array}{llrl}
\alpha=0.049-0.75 K, & \text { if } \quad K<0.045, \\
\alpha=0.015, & \text { if } \quad K>0.045 .
\end{array}
$$

The bilinear equation is depicted by red dashed line in Fig. 4, where $\alpha$ approaches the value of $0.015 \mathrm{~dB}$ per degree for high $Z_{\mathrm{DR}}$ slopes typical for continental rains.

Our analysis of the $Z-Z_{\mathrm{DR}}$ data for a large variety of rain types shows that the factor $\alpha$ generally varies between 0.01 and $0.04 \mathrm{~dB}$ per degree. The advantage of 

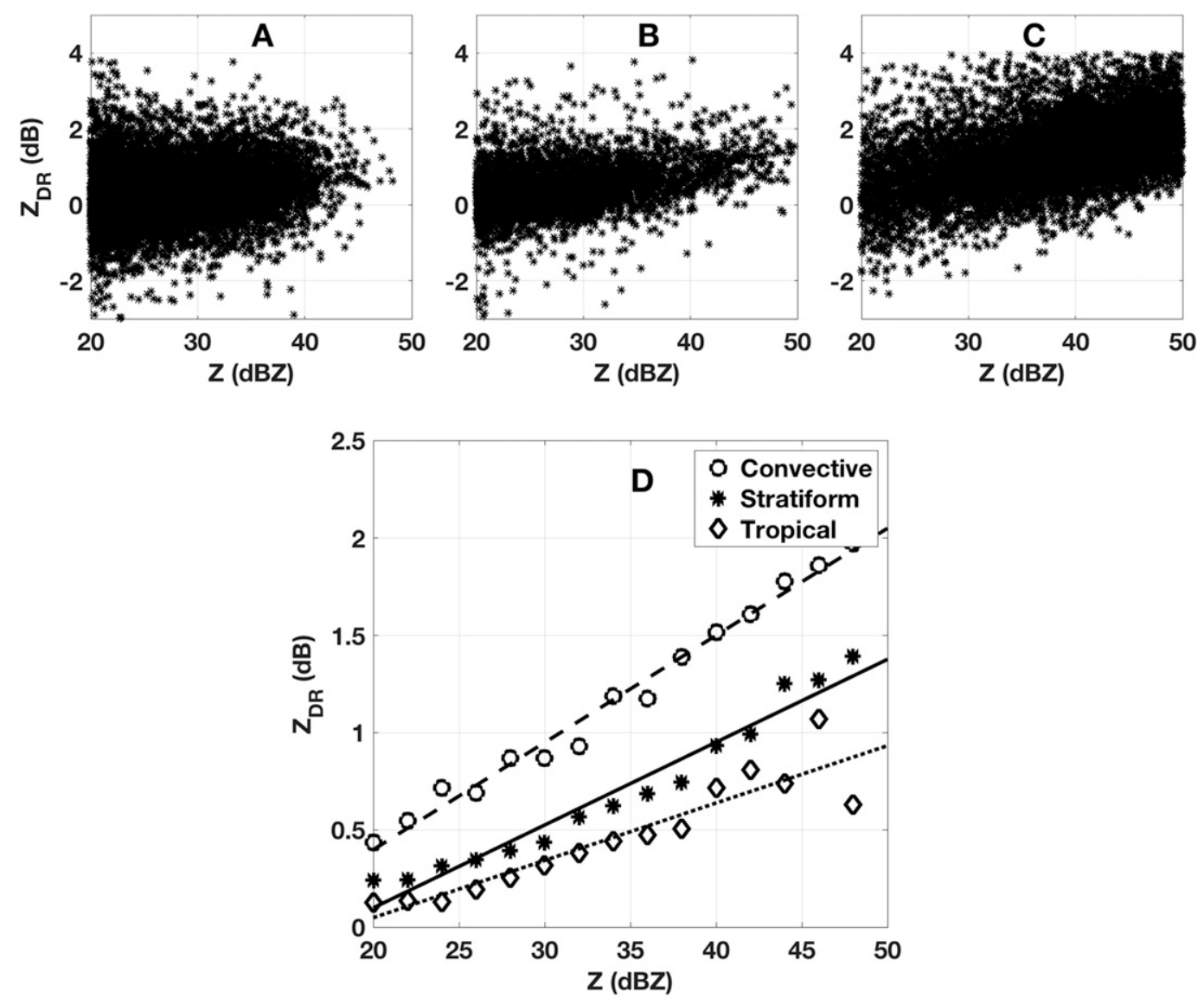

FIG. 3. Scatterplots of $Z_{\mathrm{DR}}$ vs $Z$ pairs from 24-h data (0000-2359 UTC 29 Apr 2014) collected by the KMOB WSR-88D polarimetric radar for (a) tropical, (b) stratiform, and (c) convective precipitation types, and (d) the linear fits for each precipitation type.

using the $Z_{\mathrm{DR}} / Z$ slope to estimate $\alpha$ is that calibration biases in either $Z_{\mathrm{DR}}$ or $Z$ are mitigated as an absolute value for either variable is not required. This is important because the current WSR-88D network still experiences calibration challenges with both $Z_{\mathrm{DR}}$ and $Z$ (Zittel et al. 2015). The parameter $\alpha$ can vary quite significantly between different rain events as well as within a particular rain event. The temporal variability of $\alpha$ for different precipitation types is discussed in the following section.

\section{2) Temporal VARIABILITy OF $\alpha$}

\section{(i) Deep convective continental storm}

Figure 5 illustrates the temporal variability of $\alpha$ for a severe convective storm event that impacted eastern Nebraska and western Iowa for the period from 2014 to 0729 UTC 3-4 June 2014. Storm Prediction Center severe weather reports indicated hail and peak winds $>35 \mathrm{~m} \mathrm{~s}^{-1}$ associated with this event. Overall, there were 194 severe hail (diameters $\geq 25.4 \mathrm{~mm}$ ) and 76 high wind (speeds $\geq 25 \mathrm{~m} \mathrm{~s}^{-1}$ ) reports and media reports indicated the storm caused substantial damage across the region. Figure 5 also showed example PPI images of $Z$ and $Z_{\mathrm{DR}}$ obtained from the Omaha, Nebraska, WSR-88D radar (KOAX) that showed the general precipitation structure at different times during the event. Within the convective cores, $Z_{\mathrm{DR}}$ was significantly higher than along their peripheries or in stratiform rain and reached values $4-6 \mathrm{~dB}$. This is a manifestation of very large raindrops originated from melting hail.

Examination of both $Z$ and $Z_{\mathrm{DR}}$ throughout the event indicated the estimated $\alpha$ for the radar FOV was strongly impacted by the presence of very strong convection characterized by high $Z_{\mathrm{DR}}$, therefore the temporal variability of $\alpha$ was fairly small and its value belongs to the "horizontal plateau" of the $\alpha\left(Z_{\mathrm{DR}}\right)$ dependence in Fig. 2, and generally ranged from 0.016 to $0.019 \mathrm{~dB}$ per degree although for short periods of time it was $>0.020 \mathrm{~dB}$ per degree. There were two brief periods when significant $\alpha$ variability occurred, between 0227 and $0345 \mathrm{UTC}$, with values larger than $0.020 \mathrm{~dB}$ per degree. 


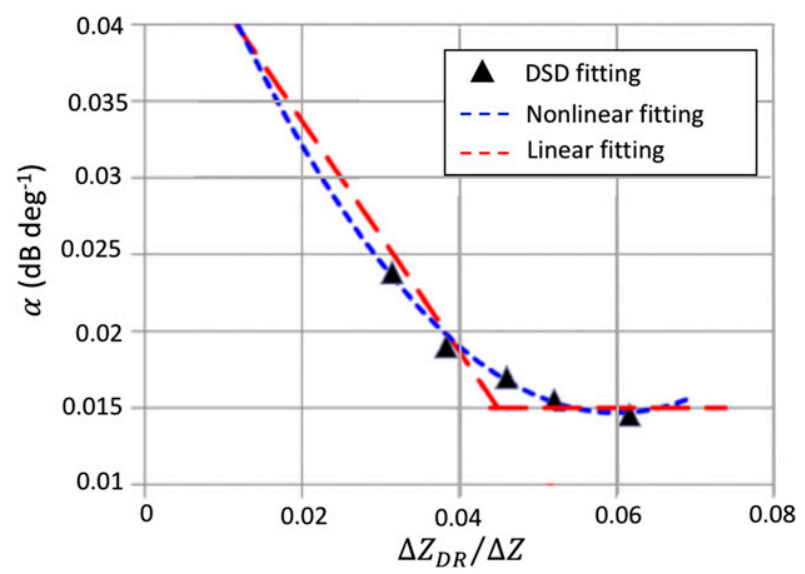

FIG. 4. The relation between factor $\alpha\left(\mathrm{dB} \mathrm{deg}^{-1}\right)$ and $Z_{\mathrm{DR}}$ slope as simulated from over 47000 DSDs collected by a disdrometer in Oklahoma. Black triangles represent each simulated variable value for the $0 \%-20 \%, 20 \%-40 \%, 40 \%-60 \%, 60 \%-80 \%, 80 \%-100 \%$ percentile groups of $Z_{\mathrm{DR}}$. The red and blue dashed lines represent the bilinear and nonlinear fits, respectively.

The $\alpha$ peaks were the result of changes in $Z_{\mathrm{DR}}$ distribution with respect to $Z$ resulting in smaller $Z_{\mathrm{DR}}-Z$ slope and therefore higher $\alpha$. An example of the scatter/numerical density plots for the second $\alpha$ peak (0327 UTC) and its subsequent decrease (0347 UTC) can be seen in Figs. $7 \mathrm{a}$ and $7 \mathrm{~b}$. The numerical density contours exhibited a shift from a flatter to a slightly steeper slope during the period, something that would be difficult to discern viewing $Z$ and $Z_{\mathrm{DR}}$ data separately. The median $Z_{\mathrm{DR}}$ also increased from $0.88 \mathrm{~dB}$ at the $\alpha$ peak (0327 UTC) to $1.13 \mathrm{~dB}$ after the peak had subsided (0347 UTC).

\section{(ii) Tropical cyclone (Hurricane Matthew)}

Much higher values of $\alpha$ are estimated during typical tropical rain event. Figure 6 shows temporal variability of $\alpha$ during Hurricane Matthew for the period from 1131 to 1200 UTC 7-8 October 2016. During this period, the hurricane was steadily weakening as it approached the Georgia and South Carolina coasts. Radar and microwave satellite imagery indicated vertical wind shear and dry air entrainment had impacted the hurricane structure so that much of the southeast hemicircle was void of deep convection. The northwest part was characterized by a broad shield of stratiform rain with some convective rainbands embedded within. Through 0200 UTC, much of the Charleston, South Carolina, WSR-88D radar (KCLX) FOV below the melting layer was dominated by stratiform rain; $\alpha$ values during this period was generally larger than $0.030 \mathrm{~dB}$ per degree. However, after this time more intense convective rainband activity and the approaching eyewall had moved into the FOV present. While $\alpha$ reached a peak $0.038 \mathrm{~dB}$ per degree at
0304 UTC, it generally decreased afterward down the value of $0.020 \mathrm{~dB}$ per degree by 1048 UTC.

The contrast between $Z$ and $Z_{\mathrm{DR}}$ imagery for Hurricane Matthew (Fig. 6) and the continental severe convective storm (Fig. 5) is quite striking. Lower $Z_{\mathrm{DR}}$ was widespread in the former whereas $Z$ and $Z_{\mathrm{DR}}$ values were significantly higher in convective cores in the latter. While $Z_{\mathrm{DR}}$ within the convective regions of the tropical cyclone (such as the eyewall) was relatively larger than in the stratiform rain areas, it was still significantly lower than in the intense convective cores for the continental convective storm. Overall, the net radar FOV $\alpha$ during Hurricane Matthew exhibited significantly higher values than in the severe convective continental storm due to the dominance of smaller drops in the former (as suggested by the $Z_{\mathrm{DR}}$ data).

Figures $7 \mathrm{c}$ and $7 \mathrm{~d}$ display the $Z_{\mathrm{DR}}$ versus $Z$ scatterplots for 0307 and 0444 UTC, the period of time when $\alpha$ showed a general decreasing trend. While the median $Z_{\mathrm{DR}}$ remained the same for both times, the best fit line for the median $Z_{\mathrm{DR}}$ for $Z$ bins between 20 and $50 \mathrm{~dB} Z$ indicates a shallower slope $K$ [Eq. (10)] which resulted in a higher $\alpha$ for 0307 UTC. A comparison of Figs. 7a and $7 \mathrm{~b}$ to Figs. $7 \mathrm{c}$ and $7 \mathrm{~d}$ reveals strong difference between continental and tropical rain regimes.

\section{c. The impact of hail on the retrieval of $A$}

The ZPHI Eqs. (3)-(5) for estimation of $A$ are valid in rain only. Therefore, the $R(A)$ estimates should be replaced by alternative rainfall relations if rain is mixed with hail or melting hydrometeors. Contamination from hail and melting layer may result in overestimation of rainfall rate.

Figures 8-10 illustrate this type of behavior in case of hail-bearing storm. The reflectivity field at the lowest antenna tilt of $0.5^{\circ}$ measured by the KMOB WSR-88D radar at 0008 UTC 4 June 2014 is displayed in Fig. 8. At that time, a few areas with $Z$ exceeding $55 \mathrm{~dB} Z$ likely contained melting hail. Radial profiles of radar variables at azimuthal direction $255.3^{\circ}$ depicted by black line in Fig. 8 are shown in Figs. 9 and 10. The region where hail was likely present was between the two black stars $\left(r_{2}=33 \mathrm{~km}\right.$, and $\left.r_{3}=48 \mathrm{~km}\right)$. The ranges $r_{1}=13 \mathrm{~km}$ and $r_{4}=85 \mathrm{~km}$ are the first and last gates comprising the radial interval where $\Delta \Phi_{\mathrm{DP}}$ and PIA are estimated, and the last gate $\left(r_{4}\right)$ is below the melting layer at elevation $0.5^{\circ}$. Radial profiles of $Z, Z_{\mathrm{DR}}, \phi_{\mathrm{DP}}$, and $\rho_{\mathrm{HV}}$ along this azimuth line are shown in Fig. 9. Between $r_{2}$ and $r_{3}, Z_{\mathrm{DR}}$ exhibits significant fluctuations ranging from 1.2 to $4.0 \mathrm{~dB}$. The $\phi_{\mathrm{DP}}$ also increased from $68.4^{\circ}$ to $129^{\circ}$ within $15 \mathrm{~km}$, but only increased $13.0^{\circ}$ between $r_{1}$ and $r_{2}$ (a 21-km distance) and $38.1^{\circ}$ between $r_{3}$ and $r_{4}$ (a 37-km distance). The steep increase in the $\phi_{\mathrm{DP}}$ field 


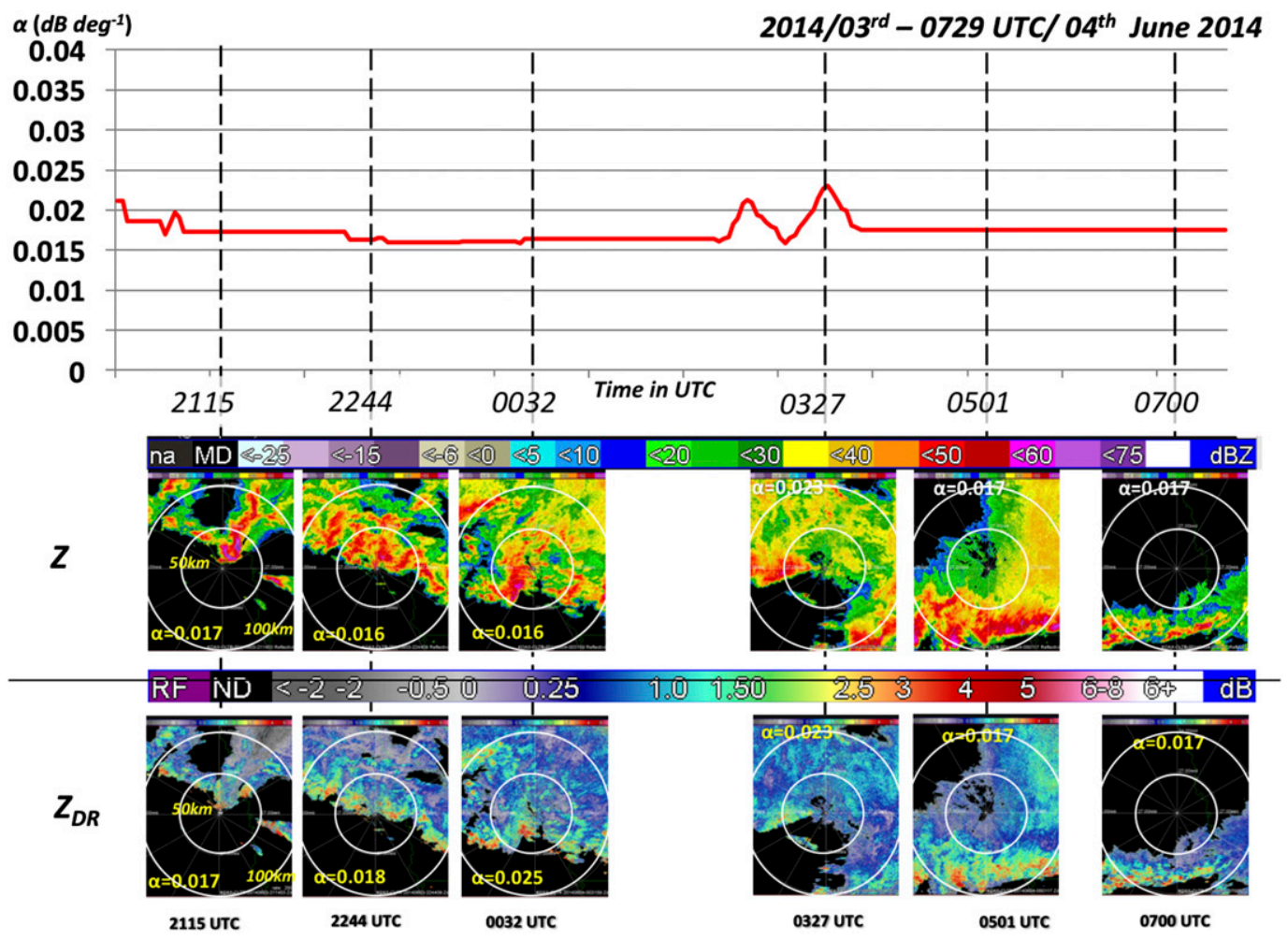

FIG. 5. (top) The temporal variability of $\alpha$ during a severe convective continental storm event on 3-4 Jun 2014. The factor $\alpha$ is calculated using $Z-Z_{\mathrm{DR}}$ pairs below the melting layer, and with $Z$ in the range between 20 and $50 \mathrm{~dB} Z$ and $\rho_{\mathrm{HV}}>0.98$. Selected time stamps are annotated and labeled with dashed black lines. (bottom) PPIs of $Z$ and $Z_{\mathrm{DR}}$ measured by the KOAX WSR-88D radar (located at the center of each image) for every time stamp with $\alpha$ labeled. Two circles with radii of 50 and $100 \mathrm{~km}$ are included to indicate the storm relative location with respect to the radar.

between $r_{2}$ and $r_{3}$ was primarily due to the presence of rain mixed with melting hail which commonly characterized by high $K_{\mathrm{DP}}$ (Ryzhkov et al. 2013). The values of $\rho_{\mathrm{HV}}$ as low as 0.92 combined with $Z>55 \mathrm{~dB} Z$ and $Z_{\mathrm{DR}}<1.5 \mathrm{~dB}$ are other indications of hail within the $\left(r_{2}, r_{3}\right)$ range interval.

The radial profile of specific attenuation $A_{1}$ estimated without segmentation between rain and hail is shown as dotted black line in Fig. 10a. If this radial profile of $A$ (marked as $A_{1}$ ) is converted to rain rate according to Eq. (9), this would produce unrealistically high values of $R$ up to $300 \mathrm{~mm} \mathrm{~h}^{-1}$ in the range interval between $r_{2}$ and $r_{3}$. Moreover, due to an integral nature of the $\mathrm{ZPHI}$ estimate, the values of $A_{1}$ outside of hail segment are also biased (dotted line in Fig. 10b). This dictates the need for the segmentation of ray and utilization of the ZPHI formulas separately in rain segments only. The corresponding estimates of $A$ are depicted as solid curves and marked as $A_{2}$ in Fig. 10a. The $A_{2}$ estimates are more realistic and are converted to more reasonable rain rates (Fig. 10b).

In the hail segment $\left(r_{2}, r_{3}\right)$, the use of the $K_{\mathrm{DP}}$-based rainfall estimator is the best option (Balakrishnan and
Zrnić 1990; Ryzhkov et al. 2013). Balakrishnan and Zrnić (1990) motivated this choice by the fact that $K_{\mathrm{DP}}$ is not affected by the presence of randomly oriented dry hailstones in the mixture with raindrops. In fact, hail mixed with rain is always wet and partially melted. Melting hail can contribute to $K_{\mathrm{DP}}$ but the contribution of very large raindrops originated from melting hail is still dominant (Ryzhkov et al. 2013). Because raindrop size distribution in the presence of hail or at the periphery hail cores is skewed toward larger drops characterized by very high $Z_{\mathrm{DR}}$, a generic $R\left(K_{\mathrm{DP}}\right)$ relation for pure rain may not be optimal. A new $R\left(K_{\mathrm{DP}}\right)$ relation using simulations in the areas classified as rain/ hail mixture was derived as

$$
R=27.0 K_{\mathrm{DP}}^{0.77}
$$

This power-law $R\left(K_{\mathrm{DP}}\right)$ has significantly smaller intercept (27.0) than the generic $R\left(K_{\mathrm{DP}}\right)$ relation $R=44.0 K_{\mathrm{DP}}^{0.82}$ (Giangrande and Ryzhkov 2008). Since the WSR-88D radars occasionally measure $K_{\mathrm{DP}}$ values as high as $7-8^{\circ} \mathrm{km}^{-1}$ in strong hail cells, utilization of the 


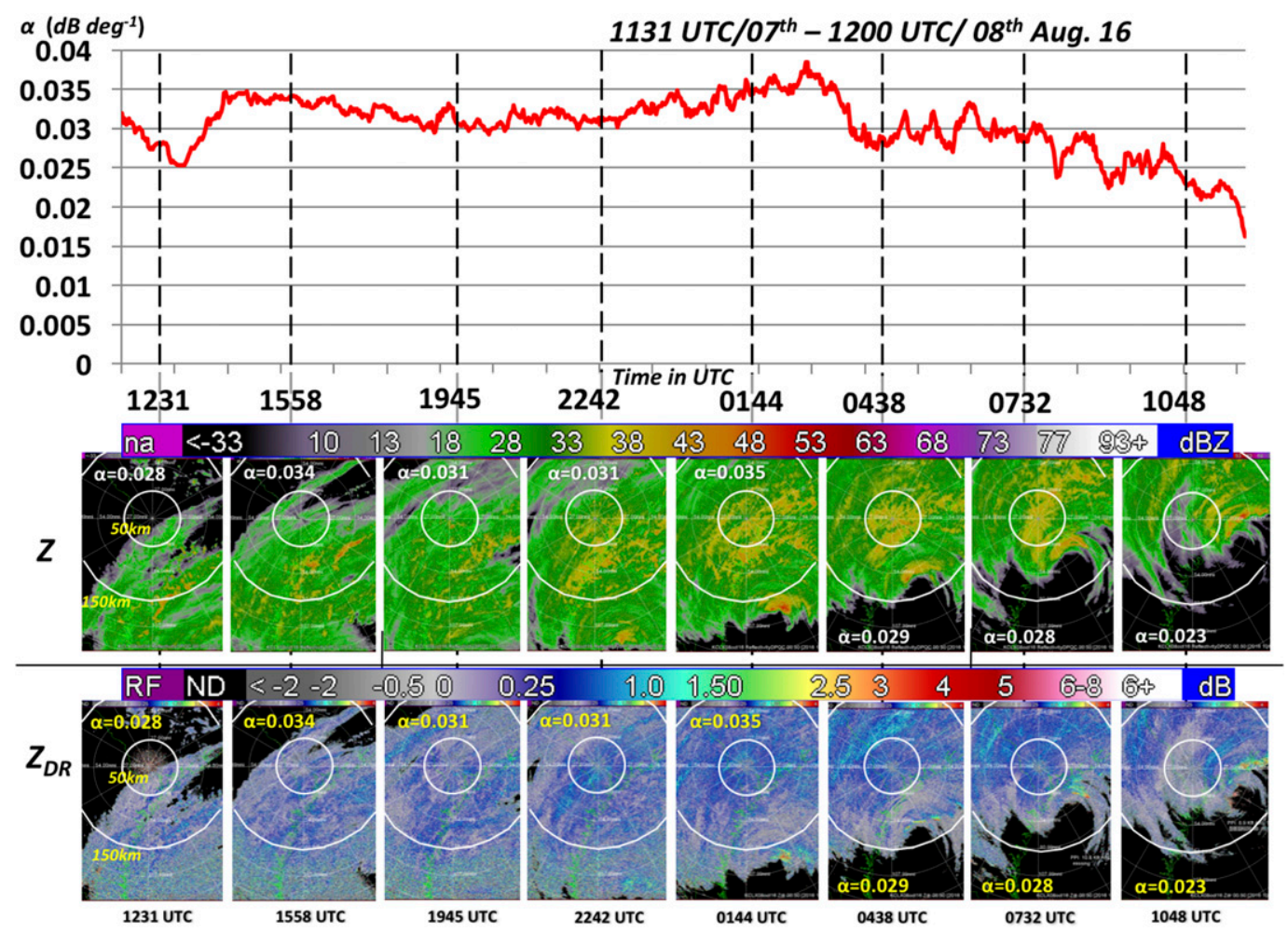

FIG. 6. As in Fig. 5, but for Hurricane Matthew observed on 7-8 Oct 2016 with the KCLX WSR-88D radar. Range circles are drawn at 50 and $150 \mathrm{~km}$ from the radar.

generic relation causes gross overestimation of rain rates there.

\section{Prototype S-band $R(A)$ algorithm}

Using the findings discussed earlier, a prototype S-band QPE algorithm utilizing specific attenuation $A$ was developed. A flowchart of the key inputs and logic used for the algorithm is shown in Fig. 11, and both the inputs $\left(Z, Z_{\mathrm{DR}}, \phi_{\mathrm{DP}}\right.$, and $\left.\rho_{\mathrm{HV}}\right)$ and outputs $(R)$ are in polar coordinates with an azimuthal resolution of $0.5^{\circ}$, radial resolution of $250 \mathrm{~m}$, and temporal resolution of approximately $5 \mathrm{~min}$. The Rapid Refresh (RAP) model sounding data (Benjamin et al. 2004), which provides heights of the $0^{\circ}, 10^{\circ}$, and $20^{\circ} \mathrm{C}$ isotherms, is used for quality control and melting layer detection. As discussed earlier, all radar data are first processed using a dualpolarization quality control algorithm (Tang et al. 2014). The range gates associated with ground clutter, anomalous propagation (AP), and nonprecipitation scatterers are identified and removed from all radar fields $\left(Z, Z_{\mathrm{DR}}\right.$, $\phi_{\mathrm{DP}}$, and $\left.\rho_{\mathrm{HV}}\right)$. The $\phi_{\mathrm{DP}}$ data are further processed via unfolding, "good data" masking, smoothing, and filling in bad data pixels (Bringi et al. 2005). The obtained smoothed $\phi_{\mathrm{DP}}$ data are used for $K_{\mathrm{DP}}$ estimation via the use of linear fitting and smoothing over 25 (9) range gates when $Z$ was less (greater) than $40 \mathrm{~dB} Z$ (Ryzhkov and Zrnić 1996; Bringi et al. 2005).

The factor $\alpha$ was estimated in real time using the approach discussed in section $2 \mathrm{~b}$ with the $Z-Z_{\mathrm{DR}}$ data from each $0.5^{\circ}$ tilt. The $Z-Z_{\mathrm{DR}}$ pairs used in the $\alpha$ estimation were selected by the following criteria: 1 ) pairs selected only from the region below the melting layer excluding hail areas, 2) $\rho_{\mathrm{HV}}>0.98$, 3) $Z_{\mathrm{DR}}$ values ranged from $-4 \mathrm{~dB}$ to $4 \mathrm{~dB}$, and 4$) Z$ ranged from 20 to $50 \mathrm{~dB} Z$. A minimum total $Z-Z_{\mathrm{DR}}$ pair number $(30000)$ is chosen to ensure a robust estimate of $\alpha$. If this threshold is not met, then the default $\alpha=0.015 \mathrm{~dB}$ per degree is used to estimate $A$. For $\alpha$ estimation, $Z-Z_{\mathrm{DR}}$ pairs were separated into sixteen 2 -dB $Z$ bins centered on $Z$ values between 20 and $50 \mathrm{~dB} Z$. The median $Z_{\mathrm{DR}}$ values for each bin are calculated, and a slope of linear fit of the $Z_{\mathrm{DR}}-Z$ dependence serves as an estimate of the $Z_{\mathrm{DR}}$ slope $K$ that is used to compute $\alpha$ from Eq. (10). It should be noted that a single parameter $\alpha$ is determined for a whole radar coverage area but the value of $\alpha$ is updated on a scan-to-scan basis. When the precipitation type is a mixture of convective, stratiform and tropical types, a single $\alpha$ may not be sufficient to capture the DSD features, and multiple $\alpha$ can provide better results. 

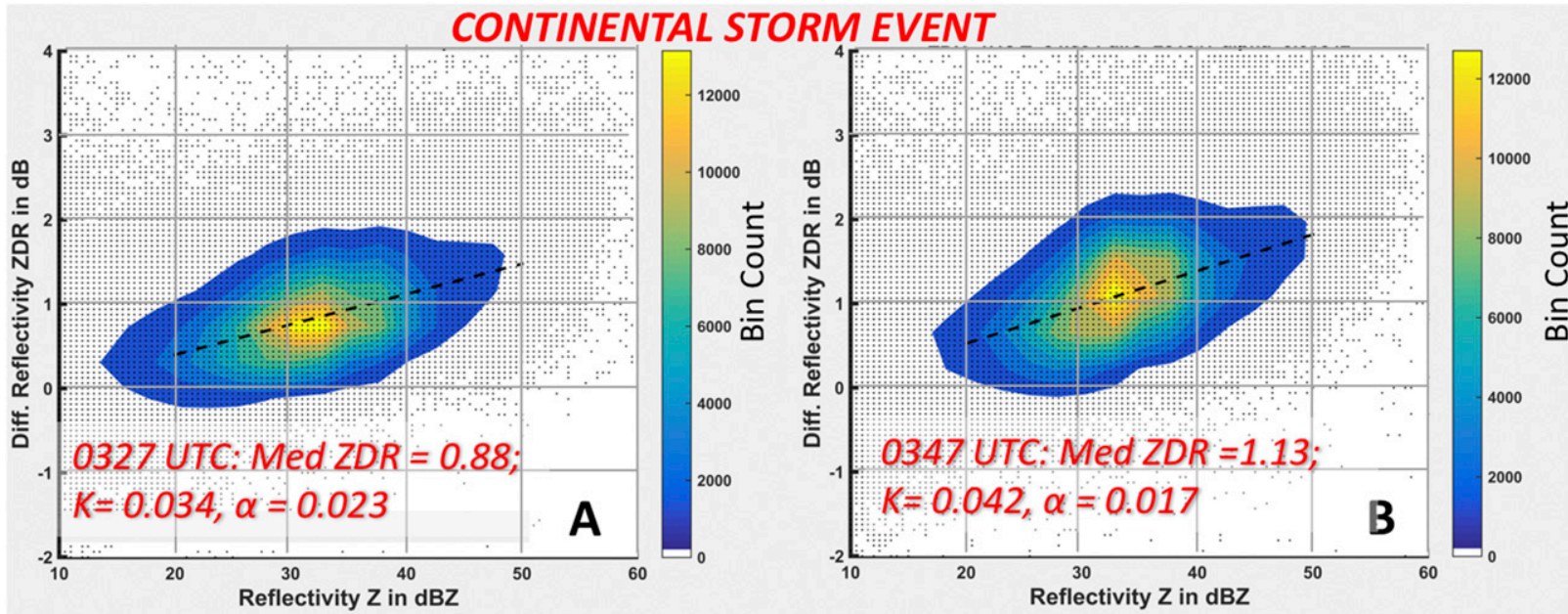

TROPICAL CYCLONE EVENT
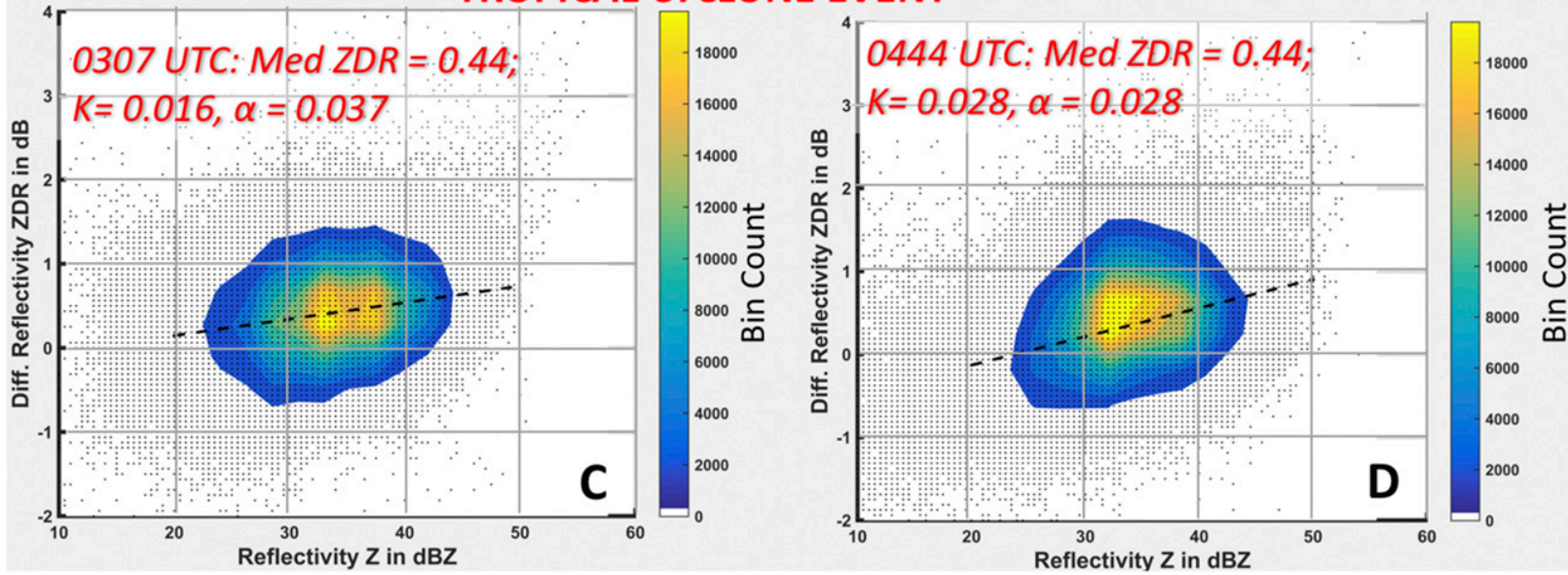

FIG. 7. Examples of distributions of $Z_{\mathrm{DR}}$ vs $Z$ from (a),(b) a continental storm event and (c),(d) a tropical cyclone event. The color bar is used to indicate the bin count of the $Z-Z_{\mathrm{DR}}$ pairs. The linear fits are depicted in each case with a dashed line. The time stamp, value of the slope $K$, factor $\alpha$, and median $Z_{\mathrm{DR}}$ are also shown for each case.

The update occurs when a sufficient number of the $Z$ $Z_{\mathrm{DR}}$ pairs (30000 in the current version) is accumulated since the last update. Therefore, the value of $\alpha$ may stay the same for a sequence of radar volume scans in the absence of extended radar echo in FOV.

Since the $R(A)$ estimate is valid in pure rain only, the range gates associated with hail, melting layer (ML), and layer above ML have to be identified. In the $A$ field estimation [Eqs. (3)-(5)], the beginning range gate $r_{1}$ is the first gate along the radial where $\rho_{\mathrm{HV}}>0.98$ and $Z>$ $5 \mathrm{~dB} Z$. The ending range gate $r_{2}$ is identified either as the last gate in the same radial where $\rho_{\mathrm{HV}}>0.98$ and $Z>$ $5 \mathrm{~dB} Z$ or the last gate where the radar beam is still below the bottom of the melting layer. The height of melting layer is determined from the Rapid Refresh (RAP) model sounding data as $H^{m}=\left(H^{0}+H^{10}\right) / 2$, where $H^{0}$ and $H^{10}$ are the heights of the $0^{\circ}$ and $10^{\circ} \mathrm{C}$ isotherms at the radar site (e.g., Benjamin et al. 2004). The $\rho_{\mathrm{HV}}$ data are examined in the proximity of the reference height $H^{m}$ and a final decision on the choice of the gate $r_{2}$ is made using the $\rho_{\mathrm{HV}}$ threshold 0.98 .

In the current version of the algorithm, a simplified version of ray segmentation is used to identify the gates attributed to nonmeteorological echo or hail. In the areas identified as contaminated by hail $(Z>50 \mathrm{dBZ})$, rain rate is computed from the $R\left(K_{\mathrm{DP}}\right)$ relation in Eq. (11). This fragmentation method provided QPE results that agreed well with gauge observations for the hail case in the current study. Large-scale validation of this prototype S-band $R(A)$ algorithm is described in the companion paper by Cocks et al. (2019, hereafter Part II).

\section{Discussion}

Although the basic version of the $R(A)+R\left(K_{\mathrm{DP}}\right)$ algorithm described in the previous section has already 


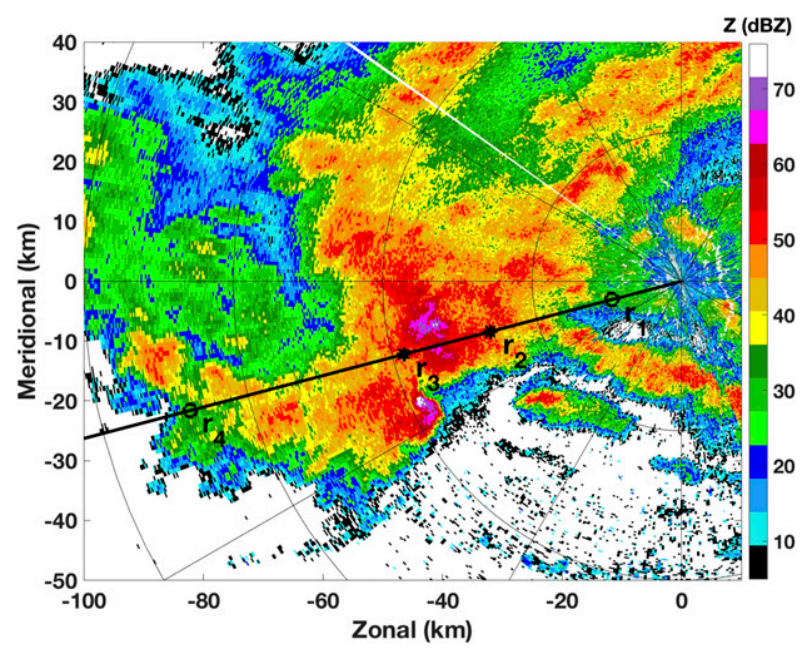

FIG. 8. The reflectivity field at 0008 UTC 4 Jun 2014 observed by the KMOB WSR-88D radar. The black line indicates the radial through hail region between $r_{2}$ and $r_{3}$.

outperformed other existing QPE algorithms as the validation study of Part II demonstrates, there is still ample room for improvement and its further optimization. Herein, we discuss possible modification strategy.

One of the potential limitations of the basic prototype $R(A)$ algorithm is the use of a single "net" value of $\alpha\left(\alpha_{0}\right)$ in a whole radar sweep. Because $\alpha_{0}$ decreases with $Z_{\mathrm{DR}}$ at $\mathrm{S}$ band (see Fig. 2), the use of the net value $\alpha_{0}$ could cause overestimation of heavier rain with high $Z_{\mathrm{DR}}$ and underestimation of lighter (or tropical) rain that is characterized by lower values of $Z_{\mathrm{DR}}$. This is conceptually illustrated in Fig. 2. If the areas of "continental" and "tropical" rain are observed in the same radar coverage area, the corresponding ranges of $Z_{\mathrm{DR}}$ are quite different and marked with two pairs of vertical yellow lines in Fig. 2. In this conceptual plot, the average value of $\alpha$ in the continental rain region is about $0.014 \mathrm{~dB}$ per degree (indicated by blue dashed line) whereas the average $\alpha$ in the tropical rain region is about $0.026 \mathrm{~dB}$ per degree. The net value of $\alpha_{0}$ averaged over the whole FOV is somewhere between these two values. Hence, indiscriminate utilization of $\alpha=\alpha_{0}$ would inevitably produce underestimation of tropical rain and overestimation of continental rain. An example of such overestimation/underestimation is reported in the study in Part II. The need for segmentation of FOV into the areas with different rain types (and different values of $\alpha$ ) is particularly important for landfalling hurricanes or typhoons which are characterized by strong spatial diversity of rain regimes. For example, strong microphysical differences between inner and outer rainbands of a tropical cyclone are often reported (e.g., Wu et al. 2018). Continued investigation of such
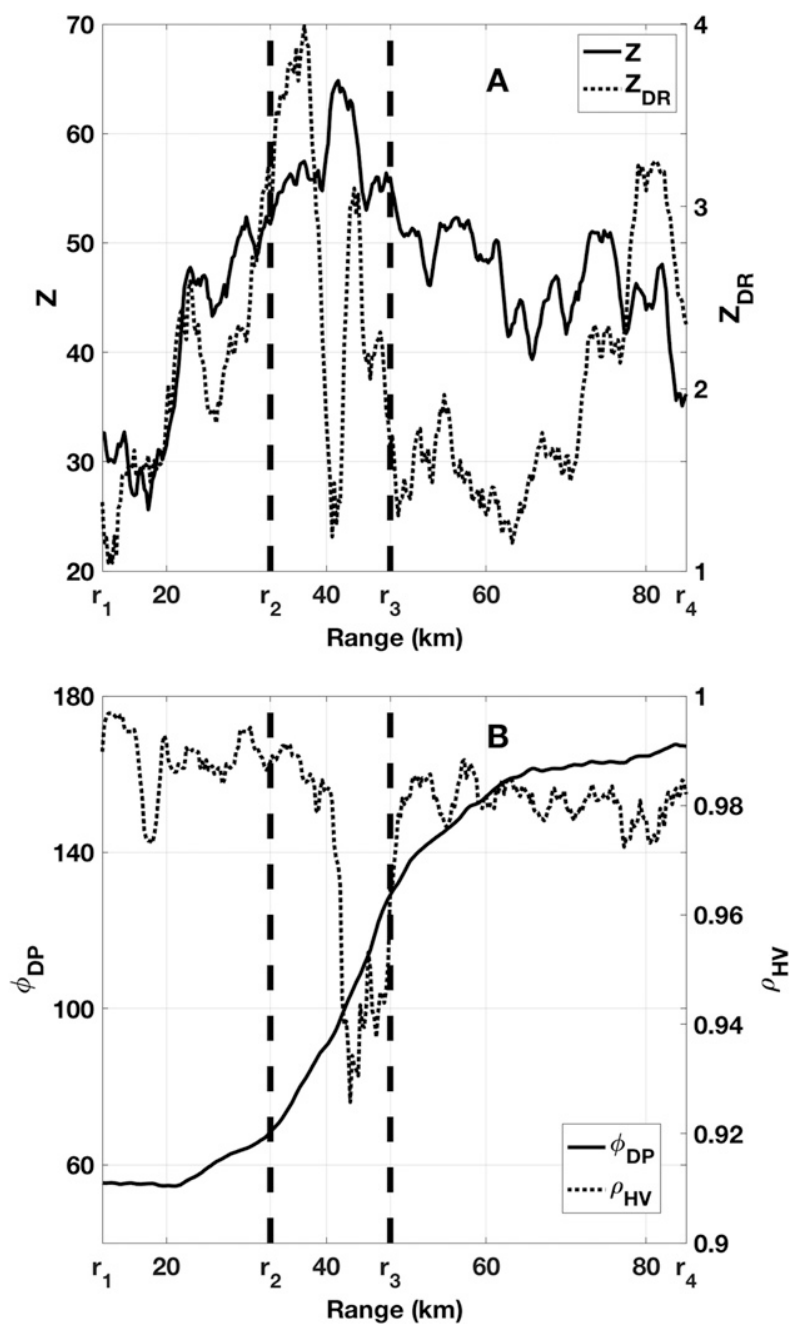

FIG. 9. Radial profiles of (a) $Z$ and $Z_{\mathrm{DR}}$ and (b) $\phi_{\mathrm{DP}}$ and $\rho_{\mathrm{HV}}$ along the azimuth indicated by the black line in Fig. 8 . The hail region is between $r_{2}$ and $r_{3}$.

cases is ongoing and further refinements and enhancements of the basic prototype $R(A)$ methodology are forthcoming.

Another potential limitation stems from characterizing essentially nonlinear dependence of $Z_{\mathrm{DR}}$ on $Z$ in rain by a single slope $K$. This slope apparently depends on the range of $Z$ in the $Z-Z_{\mathrm{DR}}$ scatterplot. The $\alpha(K)$ relation itself also depends on the choice of $Z$ range. A more advanced version of the algorithm (not discussed herein and not evaluated in the study of Part II) takes this into account.

The current $R(A)$ scheme assumes a nominal $20^{\circ} \mathrm{C}$ environment, which had not shown significant issues for radar data in the CONUS domain with the beam top below the melting layer. Nevertheless, the sensitivity of the scheme to temperature variations should be evaluated, especially for situations with long propagation 

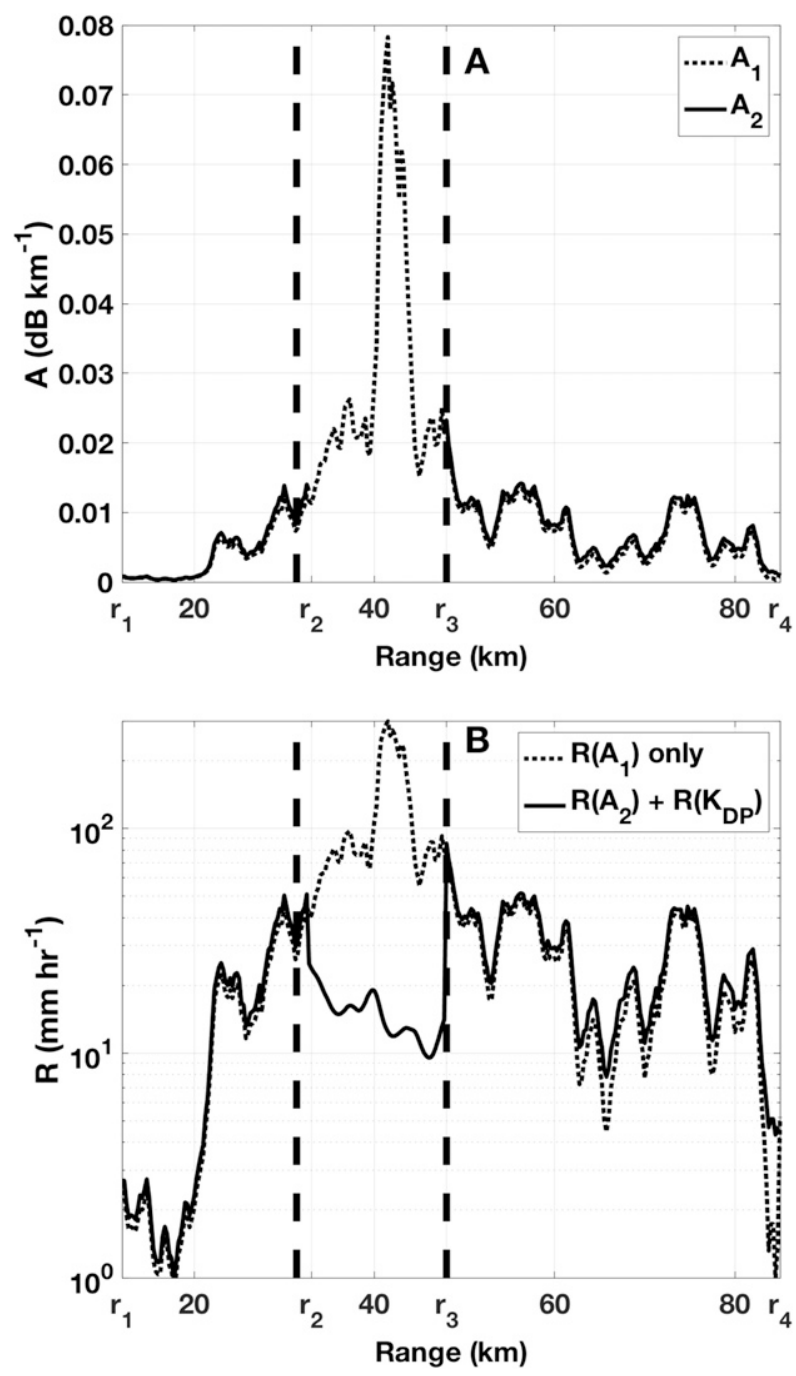

FIG. 10. (a) Radial profiles of $A$ estimated using the original approach (dotted line) and modified approach (solid line). (b) Radial profiles of rainfall rate estimated from $R(A)$ only (dotted line) and the combination of $R(A)+R\left(K_{\mathrm{DP}}\right)$ (solid line).

paths in rain and large variability of temperature (above $20^{\circ} \mathrm{C}$ ) along the path.

Finally, the current segmentation between $R(A)$ and $R\left(K_{\mathrm{DP}}\right)$ applications is based on a single reflectivity threshold and is rather simplistic. A more sophisticated segmentation procedure to account for anomalously high attenuation in wet hail may provide improved rain rate estimation and will be evaluated.

The basic version of the prototype $R(A)$ algorithm presented in this study will be further upgraded by taking into account several potential limitations inherent to the current methodology. However, despite all these potential limitations, the prototype version of the $R(A)$ algorithm described in this paper has already outperformed other QPE radar methodologies (Part II).

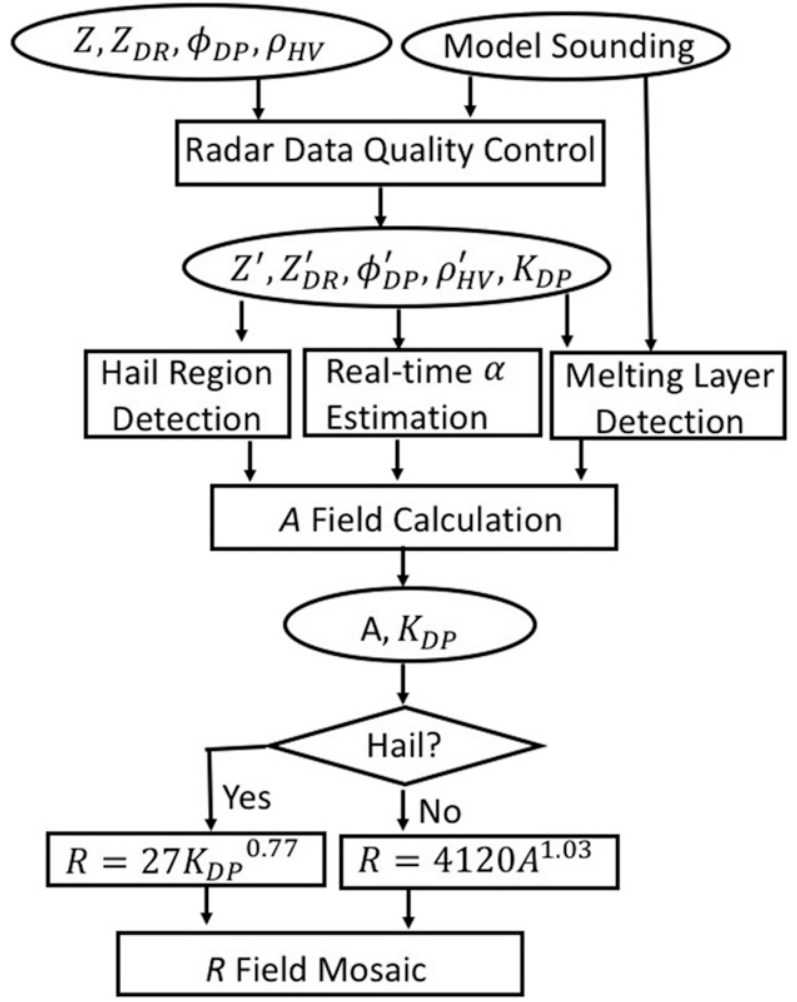

FIG. 11. The flowchart of the S-band polarimetric QPE algorithm that uses specific attenuation $A$ and specific differential phase $K_{\mathrm{DP}}$.

\section{Conclusions}

A prototype, automated QPE algorithm utilizing specific attenuation and specific differential phase $\left[R(A)+R\left(K_{\mathrm{DP}}\right)\right]$ to estimate rainfall below the melting layer was developed for use with operational polarimetric S-band radars. The algorithm uses automated procedures to avoid contamination from frozen precipitation and to optimize the net value of $\alpha=A / K_{\mathrm{DP}}$ which is crucial for conversion of differential phase into path-integrated attenuation. Although the $R(A)$ relation at $\mathrm{S}$ band is almost insensitive to the variability of drop size distributions, the estimate of $A$ is quite sensitive to the choice of $\alpha$ which depends on rain type. A methodology for determination of $\alpha$ from a slope of $Z_{\mathrm{DR}}$ dependence on $Z$ in rain is suggested in this work. According to this approach, the radar variables first go through a physically based quality control step, and those gates associated with nonprecipitation echoes are eliminated. The $Z-Z_{\mathrm{DR}}$ pairs with $Z$ between 20 and $50 \mathrm{~dB} Z$ are then grouped into sixteen $2-\mathrm{dB}$ bins, and the mean values of $Z_{\mathrm{DR}}$ from each bin are then calculated. The value of $\alpha$ is estimated using a slope of the $Z-Z_{\mathrm{DR}}$ dependence in rain which is updated on a scan-to-scan basis. The advantage of using the $Z_{\mathrm{DR}}$ slope is that it is 
almost insensitive to the miscalibration of $Z$ and $Z_{\mathrm{DR}}$. The $A$ field is then estimated with the obtained $\alpha$ for those gates with $\rho_{\mathrm{HV}}>0.98$, and $Z$ between 5 and $50 \mathrm{~dB} Z$. A "hail-adjusted" $R\left(K_{\mathrm{DP}}\right)$ relation complements $R(A)$ in areas where hail contamination is likely.

The basic version of the $R(A)+R\left(K_{\mathrm{DP}}\right)$ algorithm presented in this study will be further upgraded by taking into account several potential limitations inherent to this version. However, this preliminary version has already outperformed other QPE techniques as largescale validation efforts in Part II demonstrate.

Acknowledgments. Funding was provided by NOAA/ Office of Oceanic and Atmospheric Research under NOAA-University of Oklahoma Cooperative Agreement NA16OAR4320115, U.S. Department of Commerce, as well as the Radar Operations Center technology transfer memorandum of understanding.

\section{REFERENCES}

Balakrishnan, N., and D. Zrnić, 1990: Estimation of rain and hail rates in mixed-phase precipitation. J. Atmos. Sci., 47, 565-583, https://doi.org/10.1175/1520-0469(1990)047<0565:EORAHR > 2.0.CO;2.

Benjamin, S. G., and Coauthors, 2004: An hourly assimilationforecast cycle: The RUC. Mon. Wea. Rev., 132, 495-518, https://doi.org/10.1175/1520-0493(2004)132<0495:AHACTR> 2.0.CO;2.

Boodoo, S., D. Hudak, A. Ryzhkov, P. Zhang, N. Donaldson, D. Sills, and J. Reid, 2015: Quantitative precipitation estimation from a C-band dual-polarized radar for the 8 July 2013 flood in Toronto, Canada. J. Hydrometeor., 16, 2027-2044, https://doi.org/10.1175/JHM-D-15-0003.1.

Brandes, E. A., G. Zhang, and J. Vivekanandan, 2002: Experiments in rainfall estimation with a polarimetric radar in a subtropical environment. J. Appl. Meteor., 41, 674-685, https:// doi.org/10.1175/1520-0450(2002)041<0674:EIREWA>2.0.CO;2.

Bringi, V. N., V. Chandrasekar, N. Balakrishnan, and D. S. Zrnić, 1990: An examination of propagation effects in rainfall on polarimetric variables at microwave frequencies. J. Atmos. Oceanic Technol., 7, 829-840, https://doi.org/ 10.1175/1520-0426(1990)007<0829:AEOPEI >2.0.CO;2.

—, T. D. Keenan, and V. Chandrasekar, 2001: Correcting C-band radar reflectivity and differential reflectivity data for rain attenuation: A self-consistent method with constraints. IEEE Trans. Geosci. Remote Sens., 39, 1906-1915, https:// doi.org/10.1109/36.951081.

- M. Thurai, and R. Hannesen, 2005: Dual-Polarization Weather Radar Handbook. 2nd ed. Neuss, 163 pp.

- M. A. Rico-Ramirez, and M. Thurai, 2011: Rainfall estimation with an operational polarimetric C-band radar in the United Kingdom: Comparison with a gauge network and error analysis. J. Hydrometeor., 12, 935-954, https://doi.org/10.1175/ JHM-D-10-05013.1.

Chang, W.-Y., T.-C. C. Wang, and P.-L. Lin, 2009: Characteristics of the raindrop size distribution and drop shape relation in typhoon systems in the western Pacific from the $2 \mathrm{D}$ video disdrometer and NCU C-band polarimetric radar. J. Atmos. Oceanic Technol., 26, 1973-1993, https://doi.org/10.1175/ 2009JTECHA1236.1.

Chen, H., and V. Chandrasekar, 2015: Estimation of light rainfall using Ku-band dual-polarization radar. IEEE Trans. Geosci. Remote Sens., 53, 5197-5208, https://doi.org/10.1109/ TGRS.2015.2419212.

,-- , and R. Bechini, 2017: An improved dual-polarization radar rainfall algorithm (DROPS2.0): Application in NASA IFloodS field campaign. J. Hydrometeor., 18, 917-937, https:// doi.org/10.1175/JHM-D-16-0124.1.

Cifelli, R., V. Chandrasekar, S. Lim, P. C. Kennedy, Y. Wang, and S. A. Rutledge, 2011: A new dual-polarization radar rainfall algorithm: Application in Colorado precipitation events. J. Atmos. Oceanic Technol., 28, 352-364, https://doi.org/ 10.1175/2010JTECHA1488.1.

,,-- H. Chen, and L. E. Johnson, 2018: High resolution radar quantitative precipitation estimation in the San Francisco bay area: rainfall monitoring for the urban environment. J. Meteor. Soc. Japan, 96A, 141-155, https://doi.org/10.2151/jmsj.2018-016.

Cocks, S., L. Tang, P. Zhang, A. Ryzhkov, B. Kaney, K. L. Elmore, Y. Wang, J. Zhang, and K. Howard, 2019: A prototype quantitative precipitation estimation algorithm for operational S-band polarimetric radar utilizing specific attenuation and specific differential phase. Part II: Performance verification and case study analysis. J. Hydrometeor., 20, 999-1014, https://doi.org/10.1175/JHM-D-18-0070.1.

Diederich, M., A. V. Ryzhkov, C. Simmer, P. Zhang, and S. Tromel, 2015: Use of specific attenuation for rainfall measurement at X-band radar wavelengths. Part II: Rainfall estimation and comparison with rain gauges. J. Hydrometeor., 16, 503-516, https://doi.org/10.1175/JHM-D-14-0067.1.

Figueras i Ventura, J., A.-A. Baumahmoud, B. Fradon, P. Dupuy, and P. Tabary, 2012: Long-term monitoring of French polarimetric radar data quality and evaluation of several polarimetric quantitative precipitation estimators in ideal conditions for operational implementation at C-band. Quart. J. Roy. Meteor. Soc., 138, 2212-2228, https://doi.org/10.1002/qj.1934.

Giangrande, S., and A. Ryzhkov, 2008: Estimation of rainfall based on the results of polarimetric echo classification. J. Appl. Meteor., 47, 2445-2462, https://doi.org/10.1175/ 2008JAMC1753.1.

- S. Collis, A. Theisen, and A. Tokay, 2014: Precipitation estimation from the ARM distributed radar network during the MC3E campaign. J. Appl. Meteor. Climatol., 53, 2130-2147, https://doi.org/10.1175/JAMC-D-13-0321.1.

Gorgucci, E., G. Scarchilli, and V. Chandrasekar, 1994: A robust estimator of rainfall rate using differential reflectivity. J. Atmos. Oceanic Technol., 11, 586-592, https://doi.org/ 10.1175/1520-0426(1994)011<0586:AREORR>2.0.CO;2.

Gourley, J. J., A. J. Illingworth, and P. Tabary, 2009: Absolute calibration of radar reflectivity using redundancy of the polarization observations and implied constraints on drop shapes. J. Atmos. Oceanic Technol., 26, 689-6703, https:// doi.org/10.1175/2008JTECHA1152.1.

Mishchenko, M. I., 2000: Calculation of the amplitude matrix for a nonspherical particle in a fixed orientiation. Appl. Opt., 39, 1026-1031, https://doi.org/10.1364/AO.39.001026.

Park, S.-G., V. Bringi, V. Chandrasekar, M. Kaki, and K. Iwanami, 2005: Correction of radar reflectivity and differential reflectivity for rain attenuation at X band. Part II: Evaluation and application. J. Atmos. Oceanic Technol., 22, 1633-1655, https:// doi.org/10.1175/JTECH1804.1. 
Ryzhkov, A., and D. S. Zrnić, 1995: Comparison of dualpolarization radar estimators of rain. J. Atmos. Oceanic Technol., 12, 249-256, https://doi.org/10.1175/1520-0426(1995) 012<0249:CODPRE $>2.0 . \mathrm{CO} ; 2$

_- , and D. Zrnić, 1996: Assessment of rainfall measurement that uses specific differential phase. J. Appl. Meteor., 35, 2080-2090, https://doi.org/10.1175/1520-0450(1996)035<2080: AORMTU $>2.0 . \mathrm{CO} ; 2$.

—, M. Pinsky, A. Pokrovsky, and A. Khain, 2011: Polarimetric radar observation operator for a cloud model with spectral microphysics. J. Appl. Meteor. Climatol., 50, 873-894, https:// doi.org/10.1175/2010JAMC2363.1.

—, M. Kumjian, S. Ganson, and P. Zhang, 2013: Polarimetric radar characteristics of melting hail. Part II: Practical implications. J. Appl. Meteor. Climatol., 52, 2871-2886, https:// doi.org/10.1175/JAMC-D-13-074.1.

_- M. Diederich, P. Zhang, and C. Simmer, 2014: Potential utilization of specific attenuation for rainfall estimation, mitigation of partial beam blockage, and radar networking. J. Atmos. Oceanic Technol., 31, 599-619, https://doi.org/ 10.1175/JTECH-D-13-00038.1.

Schuur, T. J., A. V. Ryzhkov, D. S. Zrnić, and M. Schönhuber, 2001: Drop size distributions measured by a $2 \mathrm{D}$ video disdrometer: Comparison with dual-polarization radar data. J. Appl. Meteor., 40, 1019-1034, https://doi.org/10.1175/ 1520-0450(2001)040<1019:DSDMBA > 2.0.CO;2.

_ - _ , and D. R. Clabo, 2005: Climatological analysis of DSDs in Oklahoma as revealed by $2 \mathrm{D}$-video disdrometer and polarimetric WSR-88D. 32nd Conf. on Radar Meteorology, Albuquerque, NM, Amer. Meteor. Soc., 15R.4, https://ams.confex.com/ams/32Rad11Meso/techprogram/ paper_95995.htm.

Seliga, T. A., and V. N. Bringi, 1976: Potential use of the radar reflectivity and orthogonal polarizations for measuring precipitation. J. Appl. Meteor., 15, 69-76, https://doi.org/10.1175/ 1520-0450(1976)015<0069:PUORDR > 2.0.CO;2.

Tang, L., J. Zhang, C. Langston, J. Krause, K. Howard, and V. Lakshmanan, 2014: A physically based precipitationnonprecipitation radar echo classifier using polarimetric and environmental data in a real-time national system. Wea. Forecasting, 29, 1106-1118, https://doi.org/10.1175/WAF-D-13-00072.1.

Testud, J., E. Le Bouar, E. Obligis, and M. Ali-Mehenni, 2000: The rain profiling algorithm applied to polarimetric weather radar. J. Atmos. Oceanic Technol., 17, 332-356, https://doi.org/ 10.1175/1520-0426(2000)017<0332:TRPAAT>2.0.CO;2.
Thompson, E., S. Rutledge, B. Dolan, and M. Thurai, 2015: Drop size distributions and radar observations of convective and stratiform rain over the equatorial Indian and west Pacific Oceans. J. Atmos. Sci., 72, 4091-4125, https://doi.org/10.1175/ JAS-D-14-0206.1.

Vulpiani, G., M. Montopoli, L. Delli Passeri, A. Giola, P. Giordano, and F. Marzano, 2012: On the use of dual-polarized C-band radar for operational rainfall retrieval in mountainous area. J. Appl. Meteor. Climatol., 51, 405-425, https://doi.org/10.1175/ JAMC-D-10-05024.1.

Wang, Y., J. Zhang, A. V. Ryzhkov, and L. Tang, 2013: C-band polarimetric radar QPEs based on specific differential propagation phase for extreme typhoon rainfall. J. Atmos. Oceanic Technol., 30, 1354-1370, https://doi.org/10.1175/ JTECH-D-12-00083.1.

, P. Zhang, A. V. Ryzhkov, J. Zhang, and P.-L. Chang, 2014: Utilization of specific attenuation for tropical rainfall estimation in complex terrain. J. Hydrometeor., 15, 2250-2266, https://doi.org/10.1175/JHM-D-14-0003.1.

_ - J. Zhang, P.-L. Chang, C. Langston, B. Kaney, and L. Tang, 2016: Operational C-band dual-polarization radar QPE for the subtropical complex terrain of Taiwan. Adv. Meteor., 2016, 4294271, https://doi.org/10.1155/2016/4294271.

Wu, D., K. Zhao, M. Kumjian, X. Chen, H. Huang, M. Wang, A. Didlake, Y. Duan, and F. Zhang, 2018: Kinematics and microphysics of convection in the outer rainband of Typhoon Nida (2016) revealed by polarimteric radar. Mon. Wea. Rev., 146, 2147-2159, https://doi.org/10.1175/MWRD-17-0320.1.

Yoshikawa, E., T. Ushio, Z. Kawasaki, and V. Chandrasekar, 2012: Dual directional radar observation for preliminary assessment of the Ku-band broadband radar network. J. Atmos. Oceanic Technol., 29, 1757-1768, https://doi.org/10.1175/JTECH-D12-00012.1.

Zhang, J., and Coauthors, 2016: Multi-Radar Multi-Sensor (MRMS) quantitative precipitation estimation: Initial operating capabilities. Bull. Amer. Meteor. Soc., 97, 621-638, https://doi.org/10.1175/BAMS-D-14-00174.1.

Zittel, W. D., R. R. Lee, L. M. Richardson, J. G. Cunningham, J. A. Schultz, and R. L. Ice, 2015: Geographical and seasonal availability of light rain, dry snow and Bragg scatter to estimate WSR-88D $Z_{\mathrm{DR}}$ system bias. 31st Conf. on Environmental Information Processing Technologies, Phoenix, AZ, Amer. Meteor. Soc., 11.2, https://ams.confex.com/ams/95Annual/ webprogram/Paper265374.html. 